\title{
UMA BIOLOGIA AFETIVA BASEADA NO AUTOCONHECIMENTO COMO POSSIBILIDADE DE INCLUSÃO DE GÊNEROS*
}

Alice Alexandre Pagan

\section{Introdução}

Embora tenha aumentado a participação de mulheres no campo científico, o número das mesmas ainda é bem menor do que o de homens e muito menor se olharmos para quem ocupa os cargos de gestão e organização das políticas públicas sobre ciência e tecnologia, não apenas no Brasil, mas em diversas partes do mundo (LETA, 2020; AINUDDIN et al., 2005).

Diante desse cenário, diversas iniciativas têm buscado estimular o interesse e a participação de meninas nas carreiras científicas, um universo que historicamente tem sido ocupado por homens, bem como tem-se estruturado a partir de tradições e competências mais próximas aos marcadores de gênero masculino.

Uma dessas iniciativas, por exemplo, é o prêmio Mulheres na Ciência que, dentre seus critérios de seleção, considera:

A contribuição notável da candidata para o avanço geral da ciência, O impacto do corpo de trabalho da candidata no estado atual de seu campo na ciência (número, qualidade e impacto das publicações, apresentações em conferências, patentes...),

O reconhecimento da candidata pelos pares dentro de sua disciplina através de publicações,

O reconhecimento do compromisso da candidata com a educação, atividades de ensino, mentoria, etc., dentro de sua comunidade. (PRÊMIO, 2020)

Um dos problemas que podemos perceber nesses critérios, é que eles consideram que uma boa pesquisadora é aquela que tem galgado espaço nesse universo de estrutura historicamente patriarcal. Ou seja, não se propõe uma inclusão pela transformação do espaço, mas pela adaptação a

"DOI - 10.29388/978-65-86678-66-6-f.111-122 
ele. Assim, esse prêmio deveria ser considerado como aquele que retrata a mulher mais bem adaptada ao modelo de ciência masculina.

Outras iniciativas como os famosos eventos Pint of Science, que buscam discutir temas de ciência e tecnologia em uma abordagem informal como se os interessados estivessem tomando um chopp em um barzinho, também apresentam um viés ainda masculino, posto à associação cultural da cerveja ao gênero masculino (LIMA-SERRANO, LEMOS E NUNES, 2013; MOURA et al., 2018). Essa questão me faz lembrar da história de uma conhecida, pesquisadora, que às vésperas de se aposentar, sendo grande apreciadora da cerveja, me disse que finalmente, depois de anos, teve coragem de chegar sozinha em um bar e tomar uma cerveja, algo que era inconcebível para uma mulher nos tempos da juventude da mesma.

Outra iniciativa, os questionários ROSE e o Barômetro Brasil-Itália, mostram quais temas têm sido de interesse de meninas nas aulas de ciências, contudo, não problematizam o como ensinar essa ciência de maneira que ela esteja mais acessível a elas (OLIVEIRA; BIZZO; PELLEGRINE, 2016; GOUW; BIZZO, 2016).

Pesquisas no campo da inclusão tem mostrado que não basta simplesmente criar condições para que minorias tenham espaço em contextos emancipadores, é importante que esses contextos sejam repensados para dar conta das necessidades da diversidade (CANDAU, 2008).

Diante disso é possível nos perguntarmos que tipo de transformações a produção científica deveria sofrer para que se mostre mais adequada à inclusão de mulheres e demais gêneros dissidentes? Certamente que nestas poucas páginas seria impossível me comprometer com qualquer resposta, posto a complexidade da temática, que tem se estruturado como amplo campo de pesquisa. Contudo, busquei apresentar algumas reflexões tendo em vista a perspectiva da inclusão de gêneros na ciência a partir do meu lugar de fala como pesquisadora transgênero que trabalha no campo da educação científica, especificamente, ensino de biologia.

Primeiramente listei algumas características do conhecimento no campo das Ciências da Natureza, buscando confrontá-los com outras comumente associadas à marcação de gênero em nossa cultura. Importante ressaltar que defendo que aos poucos possamos superar essa ideia de marcação de gênero, posto que me parece mais libertador se vivermos sem essas caixinhas. Contudo, para que sejam feitas reflexões com vistas à inclusão, é importante descrevermos alguns desses processos demarcação. Conforme apresentou Keel (2019, p. 25), alguns pesquisadores sentem-se receosos 
em discutir marcadores de gênero, com medo de reafirmar estereótipos, contudo "[...] ao ignorar as diferenças de gênero que incontestavelmente existem, podemos estar cometendo um dano ainda maior".

Em um segundo momento apresento um breve relato da minha própria experiência no movimento de transição sobre a percepção de mudanças na atividade de pesquisa que tenho desenvolvido a partir da aceitação de minha condição de pessoa transgênero.

Por fim, apresento algumas bases ainda embrionárias de uma proposta para a redefinição da prática científica a partir da aceitação e explicitação dos elementos afetivos envolvidos nesse processo, a partir da construção do que eu tenho chamado de Biologia para o Autoconhecimento.

\section{Repensando aspectos patriarcais do conhecimento científico}

Baptista (2010, p. 682) apresentou uma síntese de características que podem ser atribuídas à ciência a partir de uma visão pragmática aceita pela comunidade científica com base na discussão de Cobern; Loving (2001 apud Baptista, 2010). Segundo ela:

(1) A ciência é um sistema explicativo naturalístico e material usado para dar conta de fenômenos naturais, que deve ser, idealmente, testável de maneira objetiva e empírica. As explicações científicas não têm como objeto, por exemplo, aspectos espirituais da experiência humana, que estão, assim, fora do escopo da investigação e do conhecimento científico. As explicações científicas são empiricamente testáveis (pelo menos, em princípio) com base nos fenômenos naturais (o teste para consistência empírica), ou com base em outras explicações científicas acerca de fenômenos naturais (o teste para consistência teórica). A ciência é um sistema explicativo, e não apenas uma descrição ad hoc dos fenômenos naturais;

(2) A ciência, como tipicamente concebida, é fundamentada em compromissos metafísicos sobre a maneira como o mundo "realmente é". Entre esses compromissos, encontram-se os pressupostos de que o conhecimento sobre a natureza é possível; de que há ordem na natureza; de que existe causação na natureza;

(3) Não obstante, é o consenso da comunidade científica que, em última instância, determina o que deve ser qualificado como ciência. Ainda que uma ideia agrupe todas as características citadas acima, 
ela só será considerada ciência se for assim julgada pela comunidade científica.

No que diz respeito ao primeiro critério, quando assumimos que a ciência é objetiva, estamos direcionando a ela um caráter que exclui os elementos não racionais, bem como afetivos que estão envolvidos no processo de construção do conhecimento (PAGAN, 2020). Atribuímos ao trabalho científico uma característica que está bastante associada à construção do masculino nos marcadores sociais de gênero de nossa cultura.

Segundo Puleo (2019) essa construção do homem duro, objetivo, tem-se mostrado historicamente como um processo de extirpação de características que são normalmente atribuídas ao feminino. Dentre elas, podemos apontar a compaixão, que é lhes tomada à medida que são estimulados a relações de predação e frieza quanto ao consumo e controle de outros animais. Essa ideia de controle acaba por ser aplicada também à muIher, que geralmente está socialmente representada no campo do natural, do animal. Ela é aquela que gera e reproduz e esse trabalho reprodutivo é controlado pelo Estado.

No que diz respeito ao segundo critério, quando falamos dos compromissos metafísicos da ciência na tentativa de mostrar o mundo como realmente é, me remeto à discussão de Ingold (1995) que mostra como temos apresentado um mundo dicotômico que propõe a separação humana frente aos demais coabitantes do planeta Terra, o que tem promovido o controle e escravização das demais espécies que são objetificadas e transformadas em produtos, representados a partir de olhares especistas, que fazem-nos acreditar que o abate e consumo de outros elementos da natureza é algo natural e impossível de evitar. Ou mesmo, me lembro da discussão de Perez, Moscovici e Chulvi (2002) que mostraram como o gradiente de hominização e animalidade tem servido à cultura ocidental para hierarquizar identidades e culturas em níveis de asselvajamento, posição na qual são representadas a mulher, as crianças, as comunidades tradicionais, que em tese, nesse viés, deveriam ser controladas e domesticadas diante de princípios colonizadores de sociedades brancas e patriarcais.

Sobre o terceiro critério, que trata do consenso da comunidade científica, é impossível deixar de assumir que ele é formado especialmente por homens brancos influenciados pela cultura europeia. Nesse sentido, busco a discussão de French (2009) que mostrou como os pesquisadores de primatas só identificavam machos alpha nos bandos investigados até que 
mulheres começaram a pesquisar, descrevendo assim, fêmeas alpha também. Isso me faz perguntar, será que descrevemos o mundo como ele é ou como nós somos? Embora os métodos procurem amenizar essa influência cultural do pesquisador, precisamos aprimorar essa crítica.

Os livros de biologia ainda discutem que corpos de cromossomos $X X$ são de mulher e $X Y$, são de homens, cometendo um grave salto de análise que desconsidera os marcadores sociais de gênero. Um corpo $X X$, manifestará útero, vagina, seios, mas daí para afirmar que esse corpo será de uma mulher tenho que levar em conta todo um processo sociocultural e psicológico de construção das subjetividades. Esse real, manifestado nos livros, que também definem aparelhos reprodutores masculinos e femininos, como se esses órgãos só servissem para a reprodução e, ainda, como se eles erroneamente, tivessem gênero, é construído com base nas projeções de uma maioria heterossexual cisgênero, que pouco se preocupa em problematizar a intersexualidade, bem como os processos identitários de pessoas trasngeneras, ageneras e demais gêneros dissidentes.

Após apresentar brevemente alguns fatores que entendo importantes de serem repensados no que consideramos como características básicas de uma prática científica, apresentei minha própria experiência de tomada de consciência das minhas posições patriarcais e suas mudanças, como pesquisadora, após minha transição de gênero.

\section{Repensando minhas práticas de pesquisa para posições menos patriarcais e mais afetivas}

Me apresentei socialmente como homem cisgênero heterossexual até os 24 anos, quando pensei que seria homossexual. Aos 35, finalmente consegui superar meus preconceitos e transfobias internalizadas, para então aceitar que na verdade eu sempre fui uma mulher, que fingiu ser homem. Vivi até os 35 anos muito mais para atender as expectativas sociais, aceitando, finalmente, que eu era uma mulher transgênera heterossexual.

Nesse processo de transição, já na condição de professora universitária e pesquisadora, pude repensar minhas práticas e redesenhar minha pesquisa ao mesmo tempo que eu reencarnava em vida, aceitando o luto daquele homem que deixava de existir e assumindo minha verdadeira identidade de gênero. Nesse processo, percebi a maravilha de poder viver mais atenta aos meus afetos e ao meu interior humano. 
Durante toda a minha vida, sofri pressões que me violentaram para engolir meus sentimentos e viver com objetividade, frieza e competitividade, ignorando as palavras medo e saudade. Construindo, portanto, uma subjetividade autodestrutiva daquela pessoa que se jogava nos embates e disputas sem qualquer cautela, bem como que não se importava de passar por cima de relações fraternas e amorosas em prol de uma carreira. Uma carreira de pesquisa que me inspirava a tentar salvar o mundo através do discurso educacional e que para tanto os fins justificariam os meios. Sempre estive na disputa de recursos e não medi esforços para fortalecer meu laboratório e minha área de pesquisa, mesmo que se necessário eu tivesse que atropelar os amigos e as amigas também colegas de trabalho.

Essa postura me trouxe inimigos e inimigas, bem como um status embasado muito mais no medo daqueles que não consideravam me enfrentar, do que necessariamente no respeito. Eu vivia estressada e mal humorada. Desenvolvia um trabalho insalubre focado na racionalidade e na objetividade, sem dar qualquer vazão aos sentimentos. Embora eu não me sentisse adaptada ao universo masculino, não era raro, alguns colegas dizerem que apesar de toda feminilidade que eu trazia, ninguém duvidasse que eu era capaz de "bater com o pinto na mesa" sempre que necessário, diante de embates, tidos como necessários.

É muito comum para quem vive a atividade de pesquisa, aceitar que se trata de uma área competitiva, na qual os embates são comuns. Eu me sentia muito adaptada a esse universo, até quando consegui tomar contato comigo mesma e perceber que o trabalho como docente e pesquisadora tinha se tornado um câncer que corroera durante anos meus outros papéis sociais.

Como descrevi no artigo Biologia para o autoconhecimento: algumas considerações autobiográficas (PAGAN, 2017), como a maioria das professoras de ciências, minhas aulas estavam baseadas na pergunta: você entendeu? Eu ignorava perguntar sobre os sentimentos dos alunos e alunas. Como você está se sentindo? Foi uma pergunta que passei a ouvir apenas depois da minha transição de gênero, e automaticamente passei a usá-la em minhas aulas, seja para saber como estavam os estudantes e as estudantes nas disciplinas que eu ministrava, como também para avaliar a mim mesma, quanto ao meu bem-estar, diante das minhas práticas pedagógicas.

Contudo, ao me deixar viver como realmente eu sou, pude perceber um novo mundo menos dicotômico, mais complexo e diverso. Nesse mundo, aprendi a perceber as nuances, os gradientes e as complexidades e 
ao mesmo tempo ganhei visibilidade. Me lembro de uma tarde, que ao sair de uma reunião, atendi uma ligação da professora Dra. Mariana Guelero do Valle, professora da Universidade Federal do Maranhão (UFMA). Ela estava emocionada e falava que tinha acabado de terminar uma palestra sobre mulheres na ciência. Nessa apresentação ela falou sobre a minha história como mulher transgênera, pesquisadora. Uma das alunas que assistia, também era mulher transgênera. Ao final, essa aluna fez um depoimento sobre o quanto se sentia representada pela discussão.

Naquele momento, me dei conta de que o meu movimento para dentro, de me aceitar e viver plenamente minha inteireza, além de salvar a mim mesma, poderia salvar outras mulheres transgêneras. Naquele momento, minha existência tornava a vida daquela aluna mais plena e eu não tinha feito qualquer movimento competitivo, agressivo ou mesmo físico. Constatei, portanto, que salvar-me era o melhor caminho para ajudar a salvar o mundo dos preconceitos, frutificar a mim mesma era uma forma de lutar contra o patriarcado.

Nesse movimento para o autoconhecimento, passei a tomar contato com meus sentimentos, com a não violência, com a cooperação, com maior integração à natureza e comecei a reivindicar esse papel para a ciência na qual eu havia me formado - a biologia.

\section{A biologia para o autoconhecimento}

A biologia para o autoconhecimento, portanto, parte da compreensão de que as relações que estabelecemos com os demais seres vivos requerem o reconhecimento de alteridades. Não somos um tipo de oposto às demais espécies do planeta. Mas, nossas relações com essas espécies participam da construção de quem somos como seres humanos (PAGAN, 2009).

Aos poucos percebo como esse discurso se aproxima das perspectivas ecofeministas posto que esse movimento social e acadêmico identifica similaridades nas opressões contra mulheres e demais seres vivos.

[...] o ecofeminismo refere-se à ideia de que a desvalorização das muIheres e da natureza tem andado de mãos dadas na sociedade ocidental patriarcal. Essa desvalorização se reforça mutuamente, por exemplo, as mulheres são associadas com a natureza e por isso são desvalorizadas; e a natureza é vista como feminina e por isso também é desvalorizada. A desvalorização das mulheres é também co- 
mumente vista como conectada com outras formas de opressão, tais quais racismo, classismo [classism], heterossexismo e especismo (KEEL, 2019, p.22)

Sendo assim, o ensino de biologia tem um papel fundamental na construção de um conhecimento que rompa com a dicotomização entre humanos e natureza, diminuindo os processos de hierarquização que ainda se refletem nas culturas ocidentais colonizadoras, que apresentam o homem branco europeu como o marco de superioridade. Nessa hierarquização, outras culturas são tidas como mais selvagens e concebidas como grupos que devem ser controlados para se adequarem às normas da branquitude heterossexual cisgênero patriarcal que se impõe implicitamente em conhecimentos científicos, políticos e religiosos, construindo um mundo bélico, focado no controle (PAGAN; EL-HANI E BIZZO, 2011).

Esse controle patriarcal, expressão do sistema de capital, que se organiza em um comportamento bélico sobre a natureza, precisa ser repensado, para uma prática mais feminina, afetiva e diplomática, que envolva o respeito como valor fundamental das relações. O respeito se mostra como balizador para pensarmos nossas aproximações e distanciamentos com relação aos elementos da natureza e consequentemente com nosso universo interior (PAGAN, 2020).

Por exemplo, se entendemos a necessidade de um banho moderado de sol, podemos angariar benefícios importantes a nossa saúde física e emocional, contudo a exposição exagerada aos raios solares, pode nos causar diversas doenças de pele, além de queimaduras. Da mesma forma, deve ser nossa relação com o mar, se ficarmos muito na beirada, não poderemos apreciar o prazer de um banho com ondas, mas se entrarmos muito fundo, a chance de afogamento será grande. Respeito se mostra como um caminho do meio, que parte do conhecimento daquele elemento e de uma interação que não seja agressiva e autoagressiva.

Respeito baliza também nossa relação com outros seres vivos. $\mathrm{Na}$ atual conjuntura da pandemia de COVID, por exemplo, uma posição de total negacionismo e distanciamento do vírus pode ser muito perigosa. Por outro lado, agir de maneira autodestrutiva, sem qualquer mudança de comportamento, batendo no peito e dizendo "vem em mim", também não nos fará sobreviver. Precisamos nos aproximar do mesmo, buscando conhecimentos necessários para convivermos sem nos afetarmos, coexistindo de maneira diplomática. 
O conhecimento patriarcal, baseado na competitividade e no consumo, seja por conta do sistema capitalista, como da ciência que ele alimenta, nos afasta da natureza e a empacota em caixas e bandejas para que possamos consumi-la. Esse afastamento nos adoece e se apresenta como uma prática que Keel (2019) definiu como um tipo de movimento suicida, que tem envenenado o planeta. Essa autora ainda aponta a importância de construirmos uma ética do cuidado, que não apenas busque regenerar a natureza que estamos destruindo fora de nós, como também que foque em cuidar do que fica dentro, nesse processo de falta e de escassez de relação afetiva com o mundo natural.

\section{Conclusão}

Quando falamos de uma biologia para o autoconhecimento, portanto, falamos de um saber que é construído em uma base que não hierarquiza razão e emoção, um saber terapêutico, que permite a construção de uma relação humano natureza que reconhece processos de alteridade. Nas aulas de ciências e biologia, práticas de visualização com olhos fechados, podem ser muito bem-vindas para a construção desse saber. Percebermos nossa própria respiração e os sentimentos que despertamos em contato com demais seres e elementos da natureza pode ser um passo bem importante para esse conhecimento.

Não faz muito tempo que em uma prática de respiração, com olhos fechados, enquanto tocávamos algumas árvores, ao final de uma aula, uma aluna me disse que o exercício havia curado sua cólica menstrual. Isso me mostrou a importância desse tipo de práticas para a inclusão feminina no campo da ciência.

Com vistas a feminilizar a prática científica, não proponho que abandonemos a razão. Mas, que possamos agregar os afetos e as percepções de cuidado e autocuidado na construção do conhecimento. Isso requer disposição para nos percebermos com inteireza nesse processo, avaliando o que mobilizamos em nós nos processos de interação com os membros da nossa própria espécie, bem como com os outros terráqueos. 


\section{Referências}

AINUDDIN, N., CARVALHO, M. G. de., FAN, P., KELAR, G., MUNDER I., TAEB, $M$. Revisiting Women's Participation in Science and Technology Emerging Challenges and Agenda for Reform. UNU-IAS Report: Yokohama, Japan, 2005

BAPTISTA, Geilsa Costa Santos. Importância da demarcação de saberes no ensino de Ciências para sociedades tradicionais. Ciênc. educ. (Bauru), Bauru , v. 16, n. 3, p. 679-694, 2010. Available from: http://www.scielo.br/ scielo.php?script=sci_arttext $\&$ pid $=$ S1516-

$73132010000300012 \& \operatorname{lng}=e n \& n r m=i s o$ access on 14 Nov.

2020. https://doi.org/10.1590/S1516-73132010000300012.

CANDAU, Vera Maria. Multiculturalismo e educação: desafios para a prática pedagógica. Cap. 1. In: Multiculturalismo, diferenças culturais e práticas pedagógicas. Antônio Flávio Moreia; Vera Maria Candau. (Orgs.). 2 ed. Petrópolis: Vozes, 2008.

FRENCH, Steven. Ciência: conceitos-chave em filosofia. Trad.: André Klaudat. Porto Alegre: Artmed, 2009, 196 pp.

GOUW, Ana Maria Santos; BIZZO, Nelio Marco Vincenzo. A percepção dos jovens brasileiros sobre suas aulas de Ciências. Educ. Rev., Curitiba, n. 60, p. 277-292, June 2016. Available from: http://www.scielo.br/scielo.php?script=sci_arttext\&pid=S010440602016000200277\&lng=en\&nrm=iso access on 14 Nov. 2020. https:// doi.org/10.1590/0104-4060.43612.

INGOLD, Tim. Humanidade e animalidade. Revista Brasileira de Ciências Sociais, n. junho, p. 1-15, 1995.

KEEL, Marti; A contribuição do ecofeminismo para a ética animal. Cap. 1. In: Ecofeminismos: fundamentos teóricos e práxis interseccionais. Daniela Rosendo; Fabio A. G. Oliveira; Patrícia Carvalho; Tânia A. Kuhnen (Orgs.). Rio de Janeiro: Ape'Ku, 2019. 
LETA, Jacqueline. As mulheres na ciência brasileira: crescimento, contrastes e um perfil de sucesso. Estud. Av., São Paulo, v. 17, n. 49, p. 271-284, Dec. 2003 . Disponível em: http://www.scielo.br/scielo.php?

script=sci_arttext \&pid=S0103-40142003000300016\&lng=en\&nrm=iso acesso em 13 Nov. 2020. https://doi.org/10.1590/S010340142003000300016.

LIMA-SERRANO, Marta; LEMOS, Ida; NUNES, Cristina. Adolescent quality of life and health behaviors: a comparative study between adolescents from the south of Portugal and Spain. Texto contexto - enferm., Florianópolis , v. 22, n. 4, p. 893-900, Dec. 2013 . Available from: http://www.scielo.br/ scielo.php?script=sci_arttext\&pid=S0104-

07072013000400004\&Ing=en\&nrm=iso . access on 15 Nov. 2020. https://doi.org/10.1590/S0104-07072013000400004.

MOURA, Luciana Ramos de et al . Fatores sociodemográficos e comportamentos de risco associados ao consumo do álcool: um recorte do Eri-

ca. Saúde debate, Rio de Janeiro, v. 42, n. spe4, p. 145-155, Dec. 2018. Available from: http://www.scielo.br/scielo.php? script=sci_arttext\&pid=S0103-11042018000800145\&lng=en\&nrm=iso . access on 15 Nov. 2020. https://doi.org/10.1590/0103-11042018s411.

OLIVEIRA, Graciela Silva; BIZZO, Nelio; PELLEGRINI, Giuseppe. Evolução biológica e os estudantes: um estudo comparativo Brasil e Itália. Ciênc. educ. (Bauru), Bauru, v. 22, n. 3, p. 689-705, Sept. 2016. Available from: http://www.scielo.br/scielo.php?script=sci_arttext\&pid=S151673132016000300689\&Ing=en\&nrm=iso. access on 14 Nov. 2020. http:// dx.doi.org/10.1590/1516-731320160030009.

PAGAN, A. A. Ser (animal) humano: evolucionismo e criacionismo nas concepções de alguns graduandos em Ciências Biológicas. 2009. 228 f. Tese (Doutorado em Educação) - Faculdade de Educação da Universidade de São Paulo, São Paulo, 2009.

PAGAN, A. A.; EL-HANI, C. N.; BIZZO, N. A identidade humana e o alter vivo: concepções de alguns alunos de Ciências Biológicas. Revista Educação Pública da UFMT, Cuiabá, v. 20, n. 44, p. 445-461, 2011. 
PAGAN, Alice Alexandre. Biologia para o Autoconhecimento: Algumas Considerações Autobiográficas. In: XI Encontro Nacional de Pesquisa em Educação em Ciências. Florianópolis/SC, Anais..., Florianópolis/SC, 2017.

PAGAN, Alice Alexandre. Entre o bélico e o diplomático: transacionar a ciência como possibilidade de humanizar a educação ambiental. Revista Sergipana de Educação Ambiental, v. 7, n. Especial, p. 1-19, 30 out. 2020. Acesso em 11 de 2020. Disponível em: https://seer.ufs.br/index.php/revisea/article/view/14387.

PÉREZ, J. A.; MOSCOVICI, S.; CHULVI, B. Natura y cultura como principio de clasificación social. Anclaje de representaciones sociales sobre minorías étnicas. Revista de Psicología Social, v. 17, n. 1, p. 51-67, 2002

PRÊMIO Internacional L'Oreal-UNESCO para mulheres na Ciência - Edição 2020. Página oficial., Notícia. 2020. Disponível em https://www.paramuIheresnaciencia.com.br/noticias/premio-internacional-loreal-unesco-paramulheres-na-ciencia-edicao-2020/. Acesso em: 12 nov. 2020

PULEO, Alicia A. Ecofeminismo: uma alternativa a la globalización androantropocéntrica. Cap. 2. In: ROSENDO, Daniela; OLIVEIRA ,Fabio A. G.; CARVALHO, Patrícia; KUHNEN, Tânia A. (Orgs.).Ecofeminismos: fundamentos teóricos e práxis interseccionais. Rio de Janeiro: Ape'Ku, 2019. 